\title{
Corrosion Behavior of X100 Steel Heat-affected Zone in Acidic Soil Solution
}

\author{
Chenqi Fu, Zhedong Xie* \\ College of Engineering and Technology, Jilin Agricultural University, Changchun Jilin 130118, China \\ *E-mail: xiezhedong09@126.com
}

Received: 21 October 2021 / Accepted: 9 December 2021 / Published: 5 January 2022

\begin{abstract}
At present, the research on X100 steel was mainly focused on the manufacturing technology, mechanical properties and welding process, while the corrosion performance of X100 steel that experienced high temperature and then formed heat-affected zone in the welding process was less studied. Therefore, in this paper, the corrosion characteristics of X100 HAZ in acidic soil solution were studied by metallographic analysis and product film morphology observation, and electrochemical method was used to study the electrochemical corrosion behavior at different $\mathrm{pH}$. The results showed that after immersion for 7 days, due to grain refinement effect, corrosion product film of X100 steel and ICHAZ generated more solid density compared to other organizations, enhanced the relative corrosion resistance. However, the product membranes of CGHAZ and IRCGHAZ were more micro defects, therefore in the late corrosion resistance decreased. The results of electrochemical experiments showed that the electrode reaction was controlled by cathode. The electrochemical reaction rate mainly depended on the film structure of corrosion products.
\end{abstract}

Keywords: X100 steel; Heat-affected zone; Acid environment; Electrochemical test

\section{$\underline{\text { FULL TEXT }}$}

(C) 2022 The Authors. Published by ESG (www.electrochemsci.org). This article is an open access article distributed under the terms and conditions of the Creative Commons Attribution license (http://creativecommons.org/licenses/by/4.0/). 